\section{Alcances de la perspectiva de género en la política cultural chilena*}

Scopes of gender perspective within Chilean cultural policy

\section{Carmen Cares-Mardones $^{* *}$}

\section{Resumen}

Dado el creciente interés de los Estados por incorporar la perspectiva de género dentro de sus políticas públicas, es necesario construir un parámetro que nos permita comprender qué tipo de discurso sobre género emana desde las instituciones gubernamentales. A través de las contribuciones de la Teoría de las Representaciones Sociales y la Teoría de Género y Registro, las políticas culturales del Estado chileno son analizadas para identificar

El artículo presentado se deriva de la investigación doctoral financiada por el Programa de Formación de Capital Humano Avanzado de CONICYT mediante la Beca de Doctorado en el Extranjero Becas Chile Folio No 71140088.

* Programa de Doctorado en Artes y Educación. Universidad de Barcelona, Legalitat, 8, 1/2, Barcelona, España. Correo electrónico: carmencares@gmail.com. las formas de representación de las mujeres como creadoras y gestoras culturales, tomando en consideración los factores contextuales que han marcado cada período en el cual han emergido.

Palabras clave: género, políticas culturales, Estado, discurso, representaciones sociales.

\begin{abstract}
Given the growing interest of States in including gender perspective into their public policies, it is necessary to construct a parameter that allows us to understand what kind of gender discourse emerges from government institutions. Through the methodological contributions of Social Representation Theory and Genre and Register Theory, the cultural policies of the Chilean State are analyzed, in order to identify forms of representation of women as creators and cultural managers, taking into account contextual factors that have marked each period in which they have emerged.
\end{abstract}

Key words: gender, cultural policies, State, discourse, social representations.

\section{Introducción}

En las últimas décadas, los gobiernos democráticos chilenos han debido revisar sus propuestas de desarrollo, considerando la existencia de una sociedad multicultural y recogiendo las exigencias internacionales sobre igualdad de género. Tanto género como cultura son conceptos que implican un análisis profundo sobre el tipo de sociedad que se desea 
construir, y para ello es imprescindible debatir sobre cómo se establece la representación de hombres y mujeres dentro de una cultura determinada, considerándose esto como el principio básico para la conformación de una sociedad equitativa y una cultura dispuesta a asumir este criterio como principal referencia.

Como primera precisión, definiré género como el concepto analítico feminista que revisa críticamente "la organización social de las relaciones entre los sexos" (Scott 2008), y que se visibiliza en el "orden simbólico con que una cultura dada elabora la diferencia sexual" (Lamas 1999:151). Para Marcela Lagarde (1996), esta perspectiva involucra el reconocimiento de la existencia de hombres y mujeres en la sociedad, y la diversidad de los géneros como el principio fundamental del desarrollo de una humanidad diversa y democrática. Esto no niega que su origen se establece dentro de la diferencia sexual biológica (Alberdi 1999; Tubert 2003), pero el interés se deposita en la construcción social de esta diferencia como la posibilidad para producir un cambio en las esferas pública y privada, en lo productivo y lo reproductivo, y en lo afectivo y lo instrumental (Banchs 1998).

Comprender el concepto de género como una estructura social y cultural que deposita sobre cuerpos biológicos determinantes de comportamiento (Braidotti 2004; Butler 2007; Mengo 2009), llama a la redefinición de las políticas de representación y a la instauración de un sistema que respete la diversidad. Esto, al parecer, ha sido complejo de comprender para las administraciones políticas, debido a que existe cierta ignorancia con respecto al término (Banchs 1998) y eso dificulta propuestas reales de cambio.
Una de las áreas donde es posible observar este problema, es en el discurso de las políticas culturales, donde la sola aparición de la palabra género supone ya una adhesión a los planteamientos de la perspectiva. En el sistema público no existe vocación para dejarse examinar con ojo crítico (Antoine 2011) y la Política Cultural chilena no ha sido objeto de cuestionamientos en torno a la materialización de las propuestas de equidad de género, más allá del balance del cumplimiento de metas administrativas. Lo anterior llama la atención, porque se han creado instituciones dedicadas a atender la diversidad de género en toda América Latina (Nivón 2013), y ello supone la existencia de voluntad para extender esto a todas las reparticiones del Estado.

Por sobre el acuerdo de las voluntades políticas en la creación de instituciones dedicadas a las mujeres, es necesario definir qué entiende el Estado por género, lo cual podemos advertir en sus discursos y en las representaciones que ofrece de los sexos. En otras palabras, es necesario rescatar las formas de representación para obtener una "instantánea" de lo que el Estado considera como propio de los hombres y de las mujeres dentro de la cultura.

El interés depositado en los documentos oficiales de sobre Política Cultural chilena se fundamenta en su importancia para el diseño del ideal social del Estado, porque las prácticas culturales no se restringen a la funcionalidad de las artes como ornamentación de otras prácticas de mayor relevancia, sino que emergen transversalmente de todas las interacciones sociales y de cualquier orden. Por ello es necesario analizar críticamente cómo se delimita el discurso político dentro de la cultura y cómo puede esto interferir en el sostenimiento 
de representaciones sociales promotoras de discriminación y sexismo.

Más allá del aparente consenso entre los diferentes sectores sobre la necesidad de generar leyes de protección a las mujeres, debe existir coherencia entre discurso y práctica. Por lo tanto, las políticas públicas deben ofrecer una representación de las mujeres como sujetos autónomos y empoderados, como principio fundamental para el total ejercicio de sus derechos (Benavente y Valdés 2014). La capacidad de agencia en igualdad de condición y la ausencia de cuestionamientos a la condición sexual -económicos, étnicos o de cualquier índole- son otorgados por el Estado, en tanto es este quien define jurídicamente a los sujetos que representa. En este sentido, el mayor riesgo que esto comporta es que los sujetos jurídicos se construyen por medio de prácticas excluyentes que legitiman la función reguladora de la ley y esconden a quienes no son representados (Butler 2007).

A través del estudio de los dos documentos oficiales que definen la Política Cultural chilena, ha sido posible identificar formas de representación de los géneros por medio de atribuciones, distinciones y acciones adjudicadas a hombres y mujeres. Esto arroja diferencias considerables para las mujeres entre los períodos 2005-2010 1 y 2011-2016², que hacen retroceder los avances sobre nuestro reconocimiento como sujetos sociales. Lo anterior no implica que a nivel institucional no existan muestras concretas (programas y

Diseñada en el Gobierno de Ricardo Lagos Escobar (2000-2006) y aplicada en el Gobierno de Michelle Bachelet Jeria (2006-2010).

2 Diseñada en el Gobierno de Sebastián Piñera Echeñique (20102014) y aplicada en el segundo Gobierno de Michelle Bachelet Jeria (2011-2016). actividades) de un interés por contribuir a la igualdad de los sexos. Sin embargo, el análisis aquí desarrollado refiere exclusivamente a lo discursivo, en su capacidad de construir realidad y sobre la base de los aportes realizados por la perspectiva de género.

El análisis de este material textual ${ }^{3}$ se basa en la aplicación de algunos conceptos de la Teoría de las Representaciones Sociales, propuesta por Moscovici (1979), en combinación con la Teoría de Género y Registro (Halliday 1982; Eggins 2002, entre otros/as), y la implicación con los Estudios del Discurso Feminista y de Género (Weatherall 2002; Tannen 2008; Wodak 2015, entre otras).

\section{Políticas con perspectiva de género}

La implementación de políticas para la igualdad de las mujeres ya se había hecho extensiva en mayor o menor medida a muchos países del globo, pero sería la IV Conferencia Mundial sobre la Mujer (celebrada en Beijíng, en 1995) la que serviría de plataforma para que el concepto de género y las nuevas nociones de diversidad ingresaran al mundo político (Guzmán 2001). Aunque su traducción del gender anglosajón como "mujeres y hombres", "uno y otro sexo", o simplemente "mujeres" (Carbajal 2002), marca un precedente de lo que en las administraciones políticas de muchos países hispanohablantes se entendería como género. De esto se desprende que gender y género no son lo mismo (Lamas 1999), tomando como parámetro comparativo el desplazamiento de los fundamentos de la teoría feminista hacia las actuales políticas de género.

Chile quiere más cultura. Definiciones de Política Cultural. 20052010 (2005) y Política Cultural 2011-2016 (2011). 
Una revisión básica de propuestas para la elaboración de políticas públicas para la diversidad arroja algo que puede ser constitutivo del problema para la implementación de la perspectiva de género en la política, lo cual alude a esta falta de conocimiento por parte de quienes construyen la noción de política pública y su implementación. Richard Zapata-Barrero (2007) enuncia que la diversidad es el resultado de una construcción social dependiente de contextos determinados, siendo esto perceptible cuando existe homogeneidad. Dentro de las categorías por él consideradas como tradicionales están la de género, minusvalía y orientación sexual, a las cuales agrega otras nuevas como edad y prácticas culturales. Pero al colocar al género como aquello que "supone temas referidos con el feminismo (mujer) ante la estructura o visión machista de la sociedad" (Zapata-Barrero 2007: 33), devalúa la posición del género como elemento transversal dentro de las diversidades y promueve una visión esencialista del feminismo, omitiendo incluso la existencia de un género masculino o considerando, quizás, que este forma parte del marco universal que construye la diferencia con las mujeres.

Esta organización conlleva una lectura implícita de que lo diverso está en oposición a algo más valorado o más aceptado. Es aquí donde el género como categoría, no únicamente femenina (en tanto distinta de sí misma e inclusiva de lo masculino) ni feminista en singular (no existe una configuración universal de feminismo), parece estar fuera de lugar. Esta categoría de género es más bien una "categoría de sexo" jerarquizada por la estructura jurídica del Estado, y que promueve la elaboración de políticas dirigidas a la inclusión de las mujeres como un bloque de diversidad unificado y sujeto a la diferenciación en relación a su antagónico hombre-masculino. Desde los primeros aportes antropológicos sobre la diferencia sexual dentro de la cultura, y que han sido bases de la teoría feminista, (Mead 1935; Ortner 1972) hasta los actuales radicados en el concepto de género e implicados con corrientes filosóficas y sociológicas (Lagarde 1996; Braidotti 2004; Butler 2007), es evidente constatar que la relación sexo/diferencia no es igual a género/diversidad, incluso cuando lo segundo pueda derivar de la definición social de la diferenciación de los sexos y ello pueda, en el mejor de los casos, construir una visión diversa dentro de las categorías asignadas.

El conflicto para la instauración de políticas de la diversidad en las sociedades actuales encuentra su origen, precisamente, en la confusión entre diferencia y diversidad, y entre sexo y género. La relación género y mujeres dentro de la política no se ha dado tan abiertamente como suponemos; han existido y siguen existiendo políticas para las mujeres (abocadas a su protección antes que a validar su aporte en el desarrollo) y políticas de género. Según Ana María Banchs (2000), las políticas para las mujeres se entienden como menos amenazadoras y son más aceptadas que las de género, porque género implica la enunciación de que existe un sistema de desigualdad donde los hombres forman el principal soporte. Sin embargo, para crear estrategias políticas que atraviesen todos los sectores del quehacer social, el término más adecuado parece ser el de género, con el consiguiente riesgo de que muchas acciones negativas atribuibles al poder machista sean definidas hoy como de género (Tubert 2003), invisibilizando la desigualdad de la que han sido y siguen siendo objeto las mujeres en un sistema históricamente masculinizado. 


\subsection{Representación política de las mujeres: La huella de la dictadura}

En los primeros años del gobierno democrático de Patricio Aylwin (1990-1994) se retoma el proyecto allendista de una institucionalidad para la protección de las mujeres; un logro concertacionista que se haría efectivo con la aparición del Servicio Nacional de la Mujer ${ }^{4}$ en 1991. El resurgir de los movimientos feministas -demonizados en dictadura y considerados enemigos de la familia, la patria y la iglesia (Grau, Delsing, Brito y Farías 1997)- dejaría sentir el descontento por la precariedad e incapacidad de esta institución para encontrar soluciones de fondo (Illanes 2012). En consecuencia, en 2015 y bajo el segundo mandato de Michelle Bachelet Jeria, se aprueba una entidad de mayor categoría y alcance: el Ministerio de la Mujer y la Equidad de Género ${ }^{5}$. Esto supone, en su implicación ideológica con el concepto de género, que sus fundamentos estarán sostenidos en un acabado conocimiento de la teoría y su labor será establecer líneas políticas de práctica. Lo anterior implica, además, que esto dará pie a nuevas formas de representar a las mujeres como sujetos jurídicos, políticos y sociales desde la propia institucionalidad del Estado.

La representación de las mujeres en Chile a partir del primer gobierno de Michelle Bachelet (2006-2010), modificó en gran medida la visibilidad de las mujeres en un área antes destinada prioritariamente a los hombres. Su imagen se levantó como emblema de la nueva y revitalizada política, pero reflejaba

Creado el 3 de enero de 1991 con la Ley № 19.023.

El 5 de marzo de 2015 se aprueba la Ley № 20.820, que crea el Ministerio de la Mujer y la Equidad de Género. aún el profundo desconocimiento que la administración tenía sobre la implementación y evaluación de las políticas de género (Checa, Lagos y Cabalin 2011). La falta de claridad sobre el real significado del concepto menguó los avances institucionales en diversidad e igualdad y, al mismo tiempo, sirvió como soporte para la elevación de una representación política de las mujeres a partir de los antiguos cimientos de la representación tradicional de las mismas.

Antonieta Vera (2009) denomina a esta representación alegórica la "mujer moderna", que no conforma en sí misma una oportunidad para escapar de la nomenclatura hegemónica, sino que adiciona más responsabilidades a las mujeres, siempre sobre la base de su rol como madres y esposas. La nueva mujer post dictadura y post Michelle Bachelet sería la misma antigua mujer de la época dictatorial, identificada por la Iglesia como pilar moral de la sociedad, pero recolocada en un rol de poder diseñado estratégicamente para ella. Tal como lo anunciaba Julieta Kirkwood (2010) a mediados de los ochenta, la izquierda chilena falló al considerar a la familia como el núcleo básico revolucionario, porque se trataba de una revolución incompleta, al no modificar la representación social de las mujeres, implicando que la transición de dictadura a democracia seguiría siendo parcial.

Las cualidades "propiamente femeninas" representadas en la "mujer moderna" cautelan la dicotomía de los sexos y sostienen el orgullo de género femenino en lo hegemónicamente destinado a sus cuerpos (Vera 2009), un peso simbólico muy bien utilizado en el gobierno de Sebastián Piñera Echeñique, posterior al primer mandato de Bachelet. En el análisis de Pamela Díaz- Romero (2010), lo anterior se ve 
reflejado en programas como Mujer, levantemos Chile; Mujer, arriba los corazones o el bono Bodas de oro, que manifiestan un exacerbado reconocimiento del valor moral de las mujeres y la institución familiar. Díaz-Romero destaca también que los acuerdos tomados por esta administración sobre género y equidad ( $\mathrm{y}$ derechos sexuales y reproductivos) en la XI Conferencia de la Mujer de Latinoamérica y el Caribe en Brasilia (2010), fueron desestimados haciendo uso de una reserva que posibilita a los gobiernos retractarse de acuerdos internacionales firmados, siendo esta la primera vez -desde el retorno a la democracia- que Chile toma una determinación semejante. Esto es un reflejo claro de que la "mujer moderna" no simboliza el empoderamiento de las mujeres como sujetos de derecho, y de que su capacidad de agencia se limita a los designios de una política de representación sexual y no a una política de ciudadanía.

Estos antecedentes marcan un presupuesto de representación que ha incidido negativamente en la apropiación de los terrenos políticos y cotidianos, al apoyar la legitimación de la relación sexo/género. Podemos considerar lo anterior como una resultante de estrategias, denominadas por José Luis Brea (2010) como "retóricas de la resistencia" y que, para estos efectos, sería la dinámica hegemónica oculta en la aceptación de la diversidad y la equidad de hombres y mujeres, sostenida ideológicamente en los mismos patrones de dominación.

\section{Género y política cultural}

La cultura ha sido objeto de interés de las teóricas feministas por ser el marco básico para las jerarquizaciones (Juliano 2001) y por permitir entender "lo que es ser una mujery lo que es ser un hombre en una sociedad concreta" (Montecino 1993: 23), apareciendo frecuentemente para justificar los comportamientos de unos y otros (Bastos 2007). Lo cultural rompe con lo natural y constituye una realidad estructurada de manera simbólica, donde se presume que en esta realidad denominada cultura lo femenino representaría la naturaleza y su caos, y lo masculino la cultura y su orden (Ortner 1972; Serret 2006). Pero ello no afirma la existencia de una visión universal y transcultural sobre dos fuerzas dicotómicas en constante disputa; más bien, y como dice Sherry Ortner (2006) -corrigiendo sus postulados del año 1972-, los significados de naturaleza y cultura no son universales, como tampoco lo es la supuesta dominación que la cultura ejerce sobre la naturaleza. Esto aun cuando lo que la propia Ortner pone en cuestión no es que socialmente no exista una concepción que avale la relación naturaleza-mujer/cultura-hombre, sino que ello sea el principio de la desigualdad.

La función "re-presentativa", como denomina Norbert Lechner a la acción del Estado para con los ciudadanos, no es la de servir de agente a uno u otro grupo social, "sino representar simbólicamente el proceso social en su conjunto" (1981: 1081). Si el Estado es garante de los derechos de sus ciudadanos pero no es responsable de la representación de los mismos, se sobrentiende que en su efecto no avala ni niega la existencia de sujetos en su individualidad, sino que los presenta bajo una perspectiva de ciudadanía amplia y sin sesgos. Esto constituye un ideal otorgado por medio de la deconstrucción de la noción de ciudadanía, para lo cual ha sido necesario reconocer la existencia de diferencias entre los sujetos que la componen. 
En vez de negar la representación, se ha vuelto políticamente correcto enunciar la "presencia" diversa de cada conformación social (etnia, sexo, edad, etc.). Se trata de una tarea que avanza lentamente pero que, principalmente en América Latina -dada su destacada condición pluricultural- se ha vuelto un principio básico para la conformación de la política pública (Nivón 2013), algo que, al menos teóricamente, tampoco está ausente de la elaboración de las políticas culturales.

María Julia Logiódice (2012) considera que las políticas culturales se relacionan con los modos de vida de las sociedades, básicamente porque la cultura no remite sólo a las artes y ello conlleva una visión mucho más amplia de su labor. A esto se suma, además, que la propia política ha dejado de ser entendida únicamente como administradora de las formas de vida y ha pasado a tener un rol de relevancia como constructora de la sociedad. Por lo tanto, la política cultural no es sólo una política del desarrollo de las artes o de conservación del patrimonio, sino una política de diseño social, en la cual el Estado no es sólo un intermediario entre lo establecido y lo deseado, sino un posibilitador de cambios.

Si bien la política cultural es algo institucionalmente reciente (Antoine 2011) comparando con otras políticas públicas, su ejercicio ha sido practicado en todos los tiempos (Güell 2012; Nivón, 2013) en el empleo de los bienes simbólicos de las sociedades para dominar a otras y para introducir sus ideologías religiosas, políticas o nacionalistas. Su emergencia, asociada a la Declaración de Derechos Humanos (1948) y de Naciones Unidas (1946), se constituyó como un garante para asegurar los derechos individuales (Logiódice
2012), para reflexionar sobre el tipo de sociedad que se desea construir y para preguntarse hasta dónde puede intervenir la institución superior del Estado (Muñoz del Campo 2011).

Pedro Güell y Tomás Peters (2011) reconocen que, a pesar de que la Política Cultural tiene importancia dentro de las políticas públicas, parece existir poco interés por efectuar análisis que no estén condicionados a las fórmulas administrativas y existen muy pocas evaluaciones sobre sus alcances (Antoine 2011). Es decir, las políticas culturales existen pero no propician debate crítico al mismo nivel que otras políticas públicas más inmediatas o mediáticamente más visibilizadas, como las educativas o las económicas.

La Política Cultural chilena no surge, específicamente, por la necesidad de dar reconocimiento a la diversidad ciudadana, aunque esto no haya sido impedimento para que sí emergiera como un potencial para su desarrollo. El urgente cambio cultural estuvo promovido por la imperiosa necesidad de subvertir los patrones dictatoriales y de crear una imagen país de estabilidad y desarrollo social. Se trató de una reconstrucción cultural desde la soberanía democrática, para lo cual era necesaria la participación de todos los ciudadanos y, en tanto miembros de una nación unificada en un Estado de derecho, correspondía reorientar la identidad cultural sobre esas líneas.

El primer gobierno democrático, liderado por Patricio Aylwin, además de constituir el Servicio Nacional de la Mujer, anuncia en su programa presidencial el proyecto de Política Cultural del Estado de Chile. La División Nacional de Cultura (1997) antecedería a lo que posteriormente se denominaría Consejo Nacional de la Cultura y las 
Artes $^{6}$, el que tendría como una de sus funciones la conformación de la industria cultural chilena para apoyar al desarrollo de nuevas fuentes de empleo y riquezas para el país. Lo anterior se acerca peligrosamente a la prestación económica del positivismo y el capitalismo a las clases dominantes, que en este caso refiere directamente (aunque no de manera única) al poder del Estado como regulador cultural.

Luis Aguirre (2007) analiza el documento Chile quiere más cultura. Definiciones de Política Cultural. 2005-2010, en el cual se materializan las primeras políticas culturales del Consejo Nacional de la Cultura y las Artes del Gobierno de Chile. En él se refleja tanto la proyección y la estructura, como los actores que participarán y las relaciones que se podrán gestar en el marco de la constitución de la Política Cultural. Las políticas cumplirían su función como controladoras al servir como filtros para fortalecer la identidad cultural y evitar los efectos negativos de la globalización, siendo desde la visión de sus creadores "la representación de la cultura y de la sociedad chilena" (Aguirre 2007: 320).

En este documento se definen algunos lineamientos clave que dan pie a la construcción deuna institucionalidad que daacceso a los bienes culturales para aquellos de menores recursos y/o de los sectores más aislados, al mismo tiempo que promueve la creación artística y apunta a que esta se convierta en un bien sustentable. A partir de aquí, la adopción del sentido de rentabilidad e industria cultural adquiere fuerza. Es por ello que, quizás, Cristian Antoine (2011) se detiene en el Fondo Nacional de Desarrollo Cultural (FONDART, creado en 2003), y concluye

Creado por la Ley 19.891, que entró en vigencia el 23 de agosto de 2003 bajo el gobierno de Ricardo Lagos Escobar. que a pesar de que este posee mecanismos para constatar el uso de los recursos asignados, no ofrece formas para evaluar su impacto social o su rentabilidad económica.

Digamosquehastaahoranos hemos concentrado más en hacer un balance sobre el cumplimiento de metas establecidas que en reflexionar sobre el cómo esas propuestas están influyendo en la sociedad. En este sentido, es destacable la ausencia de estudios sobre política cultural y género, sobre todo tomando en consideración que en el último período 2011-2016, la Política Cultural marca dentro de sus Valores y Principios la "la igualdad de género que garantice el respeto, las oportunidades y la no discriminación en la convivencia de la sociedad" (Consejo Nacional de la Cultura y las Artes 2011:52)

\section{Discurso político y representación social}

Desde la Teoría de las Representaciones Sociales (Moscovici 1979), las representaciones son un conjunto organizado de conocimientos que nos permiten ver la realidad; útil para clasificar circunstancias, fenómenos e individuos (Jodelet 1986). Como formas de cognición social (Abric 2001; van Dijk 2002), refieren a las imágenes, modelos y constructos que nos permiten intuir "Ios límites y las posibilidades de la forma en que las mujeres y los hombres actúan en el mundo" (Araya 2002). En definitiva, se trata de corpora ordenados de significantes/significados que dependen de factores de contingencia, tales como el contexto social e ideológico o la finalidad de una situación.

Según Denise Jodelet (1986), las representaciones sociales son representaciones de algo o de alguien, pero no de su ideal ni de 
lo real, y definen la identidad de un grupo por medio del control que la colectividad ejerce sobre sus miembros (Abric 2001). En este sentido, las representaciones sociales son útiles para activar mecanismos de representatividad de los colectivos (por ejemplo, el colectivo de mujeres dentro del campo político), lo que no necesariamente indica que se condiga con las intenciones político-ideológicas de esa colectividad. Esto fue revisado en el apartado 2 del presente artículo, al constatar que las atribuciones otorgadas simbólicamente a las mujeres en los espacios de poder seguían estando establecidas en el conocimiento cultural y social de estas como representantes de lo femenino en su construcción hegemónica.

Las representaciones comprenden una visión global de la realidad, pero también individual, en donde son los sujetos quienes integran las características de lo percibido a sus experiencias anteriores, y a su sistema de normas y actitudes (Abric 2001). Esto puede o no incluir un proceso mayor de reflexión crítica, pero las representaciones sociales se consideran más bien como conocimientos prácticos espontáneos (Jodelet 1986). Es decir, no existe conciencia de que aquello que enunciamos o interpretamos ha sido condicionado por una serie de procesos, y ese el mayor riesgo para la repetición de patrones de estigmatización, exclusión y desigualdad.

Los discursos no son el único lugar donde se asientan las representaciones sociales, sino además en gestos, encuentros cotidianos y claramente en la comunicación visual, que, aunque móviles, se convierten en entidades "casi tangibles" (Moscovici 1979: 29) debido a su capacidad de cristalizar. Este proceso de cristalización no es automático (Gutiérrez Vidrio
2003); no hemos construido lo que es ser una mujer en un par de semanas, sino que ha sido a través de un proceso extendido en el tiempo y se entiende que su transformación no será la resultante inmediata de imponer nuevas formas de representar.

Para Silvia Gutiérrez Vidrio (2000) no se trata de conceptualizar un discurso, sino un campo discursivo en el que se dan tipos de juegos dentro del intercambio, siendo considerable el hecho de que estos comprenden tres dimensiones principales: refieren al uso del lenguaje; a la comunicación de creencias (cognición); y a la interacción social. En conjunto, estas tres dimensiones construyen nuestra posición frente al mundo, lo que nos rodea y nos relaciona, siendo el medio en donde los hablantes construimos una "particular representación de los acontecimientos, de las relaciones sociales, y de nosotros mismos" (Martín Rojo 2003: 158).

La inmaterialidad del discurso, dictada por su sentido y su estructura verbal, se corresponde con una abstracción teórica o una construcción mental (van Dijk 2002) que no tiene propiamente un significado más allá de aquel otorgado por sus usuarios (van Dijk 1997). No pretenden ser reconocidos como expresiones de la práctica social y sirven, más bien, a fines específicos, porque están regulados y vinculados a la acción: están institucionalizados (Jäguer 2003) y "operan por reglas determinadas por estructuras de dominio" (Aguirre 2007: 328). Su importancia está dictada por su capacidad para traducir sistemas de dominación y sus respuestas; por lo tanto es medio y objetivo (Foucault 1999). Por otro lado, el "poder" dentro de las instituciones se entiende como aquello que permite a determinados agentes alcanzar sus fines, siendo las relaciones de dominación 
formas específicas de las relaciones de poder, pero no necesariamente "co-extensivas" a ellas (Gutiérrez Vidrio 2000).

El principio básico del campo de la política son las diferencias y similitudes ideológicas entre los grupos(van Dijk2005), y cuando estas diferencias se corresponden con un proceso sistemático de asimetría y se excluye significativamente a algunos por medio del ejercicio de poder de otros, estaremos hablando de dominación (Gutiérrez Vidrio 2000). A partir de esto, además, podemos intuir que el reconocimiento de esta asimetría excluyente sólo es posible a partir del enfrentamiento con otra ideología. Para que la dominación de las mujeres fuese contemplada como la resultante de una histórica asimetría con las estructuras de la masculinidad, fue necesario que existiese una ideología feminista. Esta, a pesar de sus esfuerzos en la búsqueda de alianzas con otros dominados (abolición de la esclavitud, movimientos obreros, etc.), siempre ha estado marginada de los discursos de la política contestataria en los movimientos masculinos (Kirkwood 2010).

El lenguaje y, propiamente, el discurso como el medio específico donde se materializa la ideología (Gutiérrez Vidrio 2000), ha sido una de las áreas más complejas para el abordaje de la perspectiva feminista $y$, ciertamente, la más importante. Su constitución como elemento comunicacional, constructivo y reproductivo de la esencia de universalidad hegemónica lo sitúa como el lugar propicio para la radicación de prejuicios, estereotipos y representaciones negativas (Santander 2011). Lo anterior es potencialmente observable no sólo dentro del campo de la política, sino además en lo cotidiano como reflejo de la dicotomía sexual (Weatherall 2002; Wodak 2015).
Los discursos no son autonómicos y requieren de agentes para interpretar, seleccionar y distribuir (Mozejko y Costa 2000), considerando la existencia de una relación intrínseca entre poder y lenguaje. $Y$ aunque los discursos no otorgan toda la información sobre la realidad social, son útiles para encontrar claves para reconstruirla (Gutiérrez Vidrio 2000) y, por ende, para identificar nociones de los contextos que la propician y probables opciones para contrarrestar sus efectos nocivos.

\section{Metodología y análisis}

La Teoría de las Representaciones Sociales ha recibido un sinnúmero de críticas desde diferentes perspectivas, a pesar de que sea hoy una de las más consideradas dentro de las propuestas nacidas de la Psicología Social. Natalia Chourio (2012) manifiesta que el mundo de la postmodernidad ha descontextualizado el marco de la Psicología Social para el estudio de la representación, siendo más efectiva su interacción como Psicología Discursiva, en la cual el lenguaje es comprendido por su uso más que por su interpretación. Por otro lado, Jonathan Potter y Derek Edwards (1999) concluyen que si bien podemos entender las representaciones sociales como imágenes 0 nociones mentales, estas se construyen en acción. Y es esta la razón por la cual se hace necesario construir estrategias metodológicas combinadas del estudio de lo discursivo como referencia representacional, sin descuidar que el discurso es principalmente acción y que las representaciones sociales se construyen por medio de procesos.

La Teoría de las Representaciones Sociales se ha fijado en lo depositario, a través de los 
procesos de estructuración de objetivación y anclaje (propuestas por Moscovici 1979). Me referiré a ello como principio para identificar formas de representación de mujeres y hombres considerando elementos de representación naturalizados (definición de mujer y de hombre según patrones hegemónicos, como adjetivos y atributos), los que podemos considerar como preconstruidos culturales (Grize 1993).

Para subsanar la carencia de la acción dentro de estas formas cristalizadas, me apoyaré en la Teoría de Género y Registro y, más precisamente, en el sistema de transitividad, porque es un sistema que refleja procesos, participantes y circunstancias como un modo de representar modelos de la experiencia (Ghio y Fernández 2005). Para evitar toda confusión en lo relativo al concepto feminista de género (y que no se vincula teóricamente con lo enunciado en este apartado), sólo mencionaré dentro del proceso de análisis la representación social de mujeres y hombres o de lo femenino y masculino, según corresponda.

La Teoría de Género y Registro es una "teoría de la variación funcional" (Eggins y Martin 2000), originada a partir de los planteamientos de Halliday (1982) desde la Semiótica Social y la Lingüística Sistémico Funcional. Como expone Camila Cárdenas (2014), el análisis del género busca explicar ciertas elecciones lingüísticas y cómoéstas informan sobre el marcosociocultural del que emergen; y el de registro describe cómo influye el contexto inmediato sobre el uso del lenguaje. Las variables registrales de campo, tenor y modo, aportan desde su implicación con el género discursivo interesantes herramientas para el estudio de las representaciones sociales dentro de los discursos políticos. Y aun cuando en este artículo no expondré en profundidad cómo he establecido los criterios de selección de elementos útiles para esta construcción metodológica, se sobrentiende que ha sido preciso realizar un seguimiento de toda la "cadena" de configuraciones que asisten tanto a la Teoría de Representaciones Sociales como a la Teoría de Género y Registro.

La propuesta de relación entre ambas teorías en esta construcción metodológica está sostenida en el reconocimiento de los procesos de estructuración (objetivación y anclaje) dentro del sistema de transitividad. Es decir, cómo a través de los procesos representados y quienes lo realizan (nominalizaciones) dentro acciones sociales (campo) es posible identificar los conocimientos anclados a la representación de hombres y mujeres, por medio de las atribuciones o distinciones entregadas a unos $\mathrm{u}$ otros.

Por un lado, las posibilidades del sistema de transitividad para identificar a los participantes dentro de acciones específicas como sujetos/ actores o receptores pasivos, favorecen el reconocimiento de tipos de representación dentro de contextos de acción. Y por lo otro lado, las circunstancias de localización espacial y localización temporal (Ghio y Fernández 2005) otorgan un asidero epistemológico a las construcciones discursivas, propiciando distancias argumentativas (o no) e interpretativas entre un documento y otro.

Por medio de esta matriz combinada presentada en la Tabla 1, que identifica disposiciones a lo representado, he intentado establecer la relación entre conocimientos culturales cristalizados (preconstruidos culturales) y los tipos de acciones adjudicadas a los participantes representados dentro de un contexto de situación social o acción política. Para ello, he 
empleado algunos elementos de la propuesta de análisis argumentativo de Jean Blaise Grize (1996), con el fin de definir diferenciadamente la situación social por medio de la proyección valorativa y la acción política a través de las operaciones de apropiación.

Tabla 1. Matriz combinada de análisis

\begin{tabular}{|c|c|c|c|}
\hline \multicolumn{4}{|c|}{ MATRIZ COMBINADA DE ANÁLISIS } \\
\hline \multicolumn{4}{|c|}{ Teoría de Género y Registro } \\
\hline \multicolumn{4}{|c|}{ Género: Marco cultural de emergencia } \\
\hline \multicolumn{4}{|c|}{ Registro: Influencia del contexto en el discurso } \\
\hline \multicolumn{2}{|c|}{$\begin{array}{l}\text { Campo/Sig. Ideacional: } \\
\text { Acciones sociales y } \\
\text { nominalizaciones empleadas. }\end{array}$} & $\begin{array}{l}\text { Tenor/Sig. Interpersonal: } \\
\text { Relaciones de poder y } \\
\text { solidaridad. }\end{array}$ & $\begin{array}{l}\text { Modo/Sig. Textual: } \\
\text { Canal } \\
\text { Grado de formalidad }\end{array}$ \\
\hline \multicolumn{4}{|c|}{$\begin{array}{l}\text { Sistema de transitividad: Procesos mentales, materiales, conductuales, verbales, } \\
\text { existenciales y relacionales. }\end{array}$} \\
\hline \multicolumn{4}{|c|}{ Teoría de las Representaciones Sociales } \\
\hline \multicolumn{4}{|c|}{ Operaciones lógico-discursivas } \\
\hline \multicolumn{2}{|c|}{$\begin{array}{l}\text { Proyección valorativa } \\
\text { Valoración otorgada en los argumentos. }\end{array}$} & \multicolumn{2}{|c|}{$\begin{array}{l}\text { Operaciones de apropiación } \\
\text { Presentan determinaciones irrefutables sobre } \\
\text { el objeto, cuantifican, delimitan el campo, citan } \\
\text { fuentes. }\end{array}$} \\
\hline \multicolumn{4}{|c|}{ Objetivación: Cómo los elementos abstractos se vuelven algo concreto y familiar } \\
\hline $\begin{array}{l}\text { Construcción selectiva: } \\
\text { Selección de elementos } \\
\text { significativos del objeto. }\end{array}$ & $\begin{array}{l}\text { Esquematiz } \\
\text { Organizaciór } \\
\text { torno a un n }\end{array}$ & $\begin{array}{l}\text { estructurante: } \\
\text { lementos en } \\
\text { figurativo. }\end{array}$ & $\begin{array}{l}\text { Naturalización: } \\
\text { Conversión de lo simbólico } \\
\text { a lo real. }\end{array}$ \\
\hline \multicolumn{4}{|c|}{$\begin{array}{l}\text { Anclaje: Cómo los elementos previamente incorporados inciden en la elaboración de } \\
\text { representaciones. }\end{array}$} \\
\hline
\end{tabular}

Fuente: Elaboración propia. 


\subsection{Análisis de los documentos}

Para el análisis de los documentos de política cultural chilena enunciados, he recurrido a un proceso por fases, que refiere a lo expuesto en el cuadro resumen en la Tabla 1, a lo que posteriormente se ha sumado un alcance comparativo. Para estos efectos, la codificación de los documentos es la que sigue:

- PC1: Política Cultural 2005-2010. Chile quiere más cultura (CNCA 2005).

\section{- PC2: Política Cultural2011-2016 (CNCA 2011).}

La primera fase ha consistido en la identificación del género de los documentos a analizar (Teoría de Género y Registro), apoyándome en lo que Gilberto Giménez (1981) ha propuesto sobre discurso político, el cual sería aquel caracterizado por una excesiva argumentación y que es producido por aparatos políticos que pueden delimitarse textualmente. Por ello, Giménez considera que los discursos de la política (y no los referidos a lo político) son principalmente discursos estratégicos que manifiestan "propiedades performativas (Giménez 1981: 129) porque no sólo informan sino que producen actos, asumen compromisos y toman posiciones. En base a esta definición, tanto PC1 como PC2 se corresponden como un género discursivo político-institucional.

Si bien el uso de verbos en infinitivo (o en futuro, según corresponda) es algo característico del discurso político, en PC2 -a diferencia de PC1- existe un marcado uso del tiempo verbal presente para referir a las acciones que permitirán la consecución de los objetivos planteados, algo propio de narraciones históricas o de conversaciones espontáneas y que frecuentemente se emplea para "dar visos de realidad a aquello que se cuenta" (Calsamiglia y Tusón 1999: 272). Ya que estos documentos presentan balances y comparaciones con el pasado para argumentar sus objetivos futuros, parece al menos extraña esta organización discursiva, que rompe el orden programático de los compromisos asumidos (Sánchez 2011).

Seguido a la definición del género discursivo de los textos, y para precisar fragmentos que pudieran evidenciar contenidos latentes de contenidos manifiestos, he seleccionado párrafos contenedores de palabras y conjuntos de palabras semánticamente a la representación de hombres y mujeres, que se entenderán además como nominalizaciones, siendo distinguidas en la Tabla 2 por su número de frecuencia entre paréntesis.

Parece ser una característica de los primeros años de la instauración de políticas destinadas a la equidad de los sexos, el hecho de que en PC1 conste un uso mayor de desdoblamientos léxicos que aluden, sobre todo, a la identificación de sujetos sociales bajo una denominación sociojurídica: chilenos y chilenas (3), ciudadanos y ciudadanas (2) etc. Por el contrario, en PC2 sólo se presenta con la idea todos y todas (1), citada además de un paratexto. Ambos documentos recurren primordialmente al uso de plurales masculinos, aunque sólo PC2 emplea el singular "hombre" con sentido universal (también dentro de un paratexto). Otro punto destacable es que PC1 emplea palabras como femenina (2), mujeres (2) y familias (2), para referir o relacionar balances puntuales como la situación social de las mujeres y el cambio en la configuración tradicional de la familia, empleo terminológico y temático que no se da en PC2. 
Tabla 2. Palabras y conjuntos de palabras, selección de fragmentos

\begin{tabular}{|c|c|}
\hline PC1 & PC2 \\
\hline $\begin{array}{l}\text { personas(16), chilenos(12), artistas(7), } \\
\text { sociedad(7), jóvenes(6), autores(5), } \\
\text { creadores(5), público(4), familia(4), los } \\
\text { ciudadanos(8), población(4), alumnos(6), } \\
\text { chilenos y chilenas(3) audiencias(3), } \\
\text { comunidades(3), adultos mayores(3), autor(3), } \\
\text { habitantes(3), femenina(2), mujeres(2), } \\
\text { familias(2), persona(2), ciudadanos } \\
\text { y ciudadanas(2), ciudadanía(1), los } \\
\text { afrodescendientes (1), inmigrantes(1), niños y } \\
\text { jóvenes(1), lectoras y lectores(1), hablantes(1), } \\
\text { gestores culturales(1), los estudiosos(1), , } \\
\text { miembros(1), minusválidos(1), aficionados(1), } \\
\text { cultores aficionados(1), los más jóvenes(1), } \\
\text { estudiantes(1), los otros(1), profesores(1), } \\
\text { diputados(1), padres(1), hijos(1), jefas de } \\
\text { hogar(1), artista(1), receptor(1), trabajadores(1), } \\
\text { generaciones(1). }\end{array}$ & $\begin{array}{l}\text { artistas(16), creadores(6), autor(6), hombre(4), } \\
\text { personas(3), productores(3), expertos(2), } \\
\text { chilenos(3), ciudadanos(2), ser humano(1), } \\
\text { chileno(1), curador(1), generación joven, } \\
\text { arquitectos(1), compatriotas(1), hijos, todos y } \\
\text { todas(1), artista, creador, jóvenes(1), agentes } \\
\text { (1), distribuidores(1), humanos(1), niños y } \\
\text { jóvenes(1), adultos mayores(1), académicos } \\
\text { (1), actores(1), artista(1), generación joven } \\
\text { (1), ciudadaní(1), intérpretes(1), gestores(1), } \\
\text { intermediarios(1), funcionarios(1), persona(1), } \\
\text { distribuidores(1), sociedad(1), comunidad (1), } \\
\text { distribuidores(1). }\end{array}$ \\
\hline
\end{tabular}

Fuente: Elaboración propia.

El uso del lenguaje inclusivo (Furtado 2013; Bosque 2012; García Messenguer 2001; Paredes 1995) se ha contemplado tomando en consideración las recomendaciones de la Real Academia de la Lengua Española sobre desdoblamiento léxico para plurales (Bosque 2012), pero no así el su uso de singulares masculinos generalizadores para definir acciones sociales. Esta última acción ha sido contemplada como una exclusión manifiesta de la representatividad de las mujeres en la escena social.

A partir de la selección de fragmentos, los pasos han sido el análisis de campo, tenor y modo, estacándose la relación entre las opciones de transitividad del sistema experiencial (asociado al campo) y las operaciones seleccionadas de la Teoría de las Representaciones Sociales.

La variable registral de tenor, tanto para PC1 como para PC2, se establece en una relación de solidaridad que busca persuadir e instruir a los lectores sobre la eficiencia de las medidas políticas tomadas para el desarrollo cultural, social y económico del país. Ambos carecen de terminología especializada, un lenguaje común pero formal (Eggins 2002), donde la presencia fluida de la segunda persona en plural (nosotros) dentro de PC1 instaura un tenor de relaciones de poder menos asimétrico que en PC2. 
PC2 refleja un uso constante de paratextos para sostener definiciones de arte, cultura 0 patrimonio, lo que lo acerca más bien al discurso académico, colocando al autor(a) en un rol de experto en materia cultural, y siendo un texto más denso en información pero menos preciso en argumentación política. Ambos hacen un amplio uso de construcciones elípticas, que omiten principalmente a actores dentro de las acciones en $\mathrm{PC} 2$ y responsabilidades políticas en PC1.

Tabla 3. Ejemplo de análisis de campo: Nominalizaciones y acciones sociales

\begin{tabular}{|c|c|}
\hline \multicolumn{2}{|c|}{ Variable registral de campo } \\
\hline \multicolumn{2}{|c|}{ Ejemplos de nominalización } \\
\hline PC1 & PC2 \\
\hline $\begin{array}{l}\text { Quienes aparecen como actores/ejecutores } \\
\text { representan a colectivos diversos pero definidos por } \\
\text { el tipo de aporte otorgado al desarrollo cultural. } \\
\text { a) Las mujeres aparecen como beneficiarias de los } \\
\text { cambios culturales, políticos y económicos del país, } \\
\text { junto a los estudiantes mapuche, los adultos mayores } \\
\text { y los grupos de escasos recursos. } \\
\text { b) Las mujeres son representadas como una nueva } \\
\text { fuerza de trabajo. } \\
\text { b) Los creadores, los artistas profesionales, los } \\
\text { jóvenes talentosos, los expertos, los parlamentarios } \\
\text { y los profesores son responsables del desarrollo } \\
\text { cultural. }\end{array}$ & $\begin{array}{l}\text { Actores/ejecutores están identificados como grupos } \\
\text { profesionales a los cuales se le atribuyen unas tareas } \\
\text { concretas en la creación, desarrollo y gestión de la } \\
\text { cultura y las artes. } \\
\text { a) Los hombres aparecen como los creadores del } \\
\text { arte y la cultura. } \\
\text { b) Las mujeres no son enunciadas en todo el } \\
\text { documento y bajo ningún tipo de nominalización } \\
\text { específica. Pueden encontrarse, probablemente, en } \\
\text { los plurales masculinos. } \\
\text { b) Los arquitectos, los artistas y los autores son } \\
\text { portadores de la capacidad de generar cultura. } \\
\text { c) Los gestores culturales y los funcionarios públicos } \\
\text { son responsables de la proyección cultural. }\end{array}$ \\
\hline \multicolumn{2}{|c|}{ Acciones sociales } \\
\hline $\begin{array}{l}\text { Las acciones son propias de la vida en sociedad, } \\
\text { considerándose trascendente a nivel cultural los } \\
\text { procesos educativos, económicos y laborales. Al } \\
\text { proponer una perspectiva amplia de lo que es cultura, } \\
\text { las acciones son delineadas por el micro-prisma de } \\
\text { la política. Es decir, cultura como espacio vivible y en } \\
\text { construcción permanente. }\end{array}$ & $\begin{array}{l}\text { Cultura es definido por lo patrimonial, lo artístico } \\
\text { y lo administrativo de las artes. Determinándose } \\
\text { acciones políticas destinadas a proteger la } \\
\text { concepción tradicional de cultura, no así la cultura } \\
\text { como manifestación de la vida en sociedad o cultura } \\
\text { de masas. La especificidad del término, según cómo } \\
\text { se manifiesta a través de los participantes, delimita } \\
\text { en gran medida las acciones. }\end{array}$ \\
\hline
\end{tabular}

Fuente: Elaboración propia. 
Argumentativamente, ambos documentos se sostienen en los progresos alcanzados en materia cultural, entendiéndose cultura como la amplia gama de acciones y relaciones en sociedad en PC1 y como aquellas vinculadas a la actividad artística o patrimonial en PC2. A través de las circunstancias de temporalidad, es posible detectar que la cultura es comprendida en los inicios de la institucionalidad cultural (PC1) como un conjunto de acciones y construcciones realizadas en sociedad, desde las cuales se desprenden actividades de convivencia cotidiana en las que participan todos los miembros de la comunidad. Esto se modifica en años posteriores (PC2), pasando de ser un término que abarcaba a gran parte de la población, en acción y beneficio, a una actividad realizada (como acción o gestión) por profesionales del área, es decir, artistas, intérpretes, escritores, gestores culturales, etc. El matiz de la profesionalización se diluye en los procesos relacionales y existenciales, condicionando el rol de los actores a una entidad ajena e instalada dentro de la sociedad (institución estatal) y para la cual los profesionales de la cultura cumplen una función de conductores.

La presencia de artículos femeninos dentro de un discurso no asegura la representación social de las mujeres como productoras, pero sí los procesos relacionales no basadosúnicamenteen la función doméstica, los mentales en los que se le otorga capacidad de agencia y los materiales que denotan el impacto de su participación social (Tabla 4). En PC2 la nominalización de agentes femeninos no se cumple, y en PC1 sólo está asociada a su inclusión como fuerza de trabajo y estratégicamente cercana (dentro de la generalidad física de los párrafos del texto) a su condición de madre de familia y a la evaluación del cambio en la constitución de la familia nuclear.

Al no existir nominalizaciones asociables a las mujeres como sujetos sociales en PC2 (Tabla 3), no es posible comparar los documentos en el aspecto enunciativo. El análisis de transitividad en PC1 denota que aun cuando las mujeres sí están consideradas como participantes del escenario cultural, estas solo son representadas como beneficiarias de acciones realizadas por otros. Ysi bien PC1 sí incorpora desdoblamientos léxicos como "chilenos y chilenas", estos no son atributivos de acciones específicas como la creación o la gestión cultural (Tabla 4).

Es destacable, además, que las circunstancias de temporalidad arrojan en PC2 confrontaciones en su configuración epistemológica, al emplear datos recogidos en una fecha muy anterior a la elaboración del documento y que, por tanto, sería información poco útil para efectuar balances. De igual manera, el uso de citas textuales para construir la noción de cultura es extraída de documentos oficiales de la Organización de las Naciones Unidas para la Educación, la Ciencia y la Cultura (UNESCO) y la política cultural mexicana de los años setenta y ochenta, a diferencia de PC1, que utiliza definiciones de cultura posteriores al año 2000 y datos de entre los años 2000 y 2005 (Tabla 5).

\section{Discusión}

Resulta complejo efectuar una análisis discursivo de la representación social de los géneros cuando no existen enunciaciones que permitan conectar comparativamente los textos, es decir, cuando las nominalizaciones son generales y no atribuibles a géneros o 
Tabla 4. Ejemplo de análisis en matriz combinada

\begin{tabular}{|c|c|}
\hline \multicolumn{2}{|c|}{ MATRIZ COMBINADA DE ANÁLISIS } \\
\hline \multicolumn{2}{|c|}{ Sistema de transitividad } \\
\hline \multicolumn{2}{|c|}{ Ejemplo } \\
\hline PC1 & PC2 \\
\hline $\begin{array}{l}\text { Asimismo, el país (actor impersonal) muestra } \\
\text { (proceso material) una tendencia a la inclusión } \\
\text { de las mujeres (beneficiario/participante } \\
\text { pasivo) en el mercado del trabajo (meta), } \\
\text { cuya tasa de participación se ha duplicado } \\
\text { (circunstancia de manera) en los últimostreinta } \\
\text { años (circunstancia de extensión temporal) - } \\
\text { pasando del 29,5 en } 1992 \text { al } 35,6 \% \text { en } 2002- \\
\text { (circunstancia de localización temporal/ } \\
\text { circunstancia de manera: comparación) y al } \\
\text { crecimiento de la cantidad de mujeres que } \\
\text { son (relacional identificativo) jefas de hogar } \\
\text { (atributivo) (PC1, p.9). }\end{array}$ & $\begin{array}{l}\text { La Encuesta Nacional de } 2009 \text { (actor } \\
\text { impersonal) revela (proceso verbal) una } \\
\text { franca mejoría en la percepción que los } \\
\text { chilenos tienen del acceso a la cultura (objeto } \\
\text { del discurso). El } 67 \% \text { de los consultados } \\
\text { (actor impersonal) afirma que este acceso } \\
\text { es (proceso relacional atributivo) más fácil } \\
\text { hoy que hace cinco años (circunstancia } \\
\text { de localización temporal/circunstancia de } \\
\text { manera). Un } 85 \% \text { considera que tiene mayor } \\
\text { acceso que las generaciones anteriores } \\
\text { (circunstancia de localización temporal/ } \\
\text { circunstancia de manera: comparación). } \\
\text { lgualmente, se revela (/construcción elíptica/) } \\
\text { la disminución del porcentaje de personas } \\
\text { que jamás ha asistido a algún evento de } \\
\text { cultura y arte (PC2, p. 40). }\end{array}$ \\
\hline \multicolumn{2}{|c|}{ Operaciones lógico discursivas } \\
\hline \multicolumn{2}{|c|}{ Proyección valorativa } \\
\hline $\begin{array}{l}\text { La inclusión de las mujeres al mundo } \\
\text { del trabajo se entiende dentro de una } \\
\text { construcción general que argumenta los } \\
\text { progresos alcanzados. }\end{array}$ & $\begin{array}{l}\text { El mayor acceso de los chilenos a la cultura } \\
\text { es entendido como una franca mejoría, } \\
\text { comparativamente con años anteriores. }\end{array}$ \\
\hline \multicolumn{2}{|c|}{ Operaciones de apropiación } \\
\hline $\begin{array}{l}\text { Se establece porcentual y temporalmente } \\
\text { los criterios comparativos que permiten } \\
\text { reconocer la mejora en la inclusión de las } \\
\text { mujeres al mundo laboral por medio de cifras. } \\
\text { Datos obtenidos de estudios de participación. }\end{array}$ & $\begin{array}{l}\text { Se cita referentes y se muestran porcentajes } \\
\text { de comparación que permiten reconocer la } \\
\text { mejora en el acceso a la cultura. }\end{array}$ \\
\hline
\end{tabular}

Fuente: Elaboración propia. 
Tabla 5. Ejemplo de análisis en matriz combinada.

\begin{tabular}{|c|c|}
\hline \multicolumn{2}{|c|}{ MATRIZ COMBINADA DE ANÁLISIS } \\
\hline \multicolumn{2}{|c|}{ Ejemplo } \\
\hline PC1 & PC2 \\
\hline $\begin{array}{l}\text { En nuestro país (circunstancia de localización } \\
\text { espacial) la cultura no es (proceso existencial/ } \\
\text { adj. modal negación) aún (circunstancia de } \\
\text { localización temporal) una tarea de todos } \\
\text { los chilenos y a veces sólo concierne a los } \\
\text { directamente involucrados en la creación } \\
\text { artística. Los chilenos pueden tomar (proceso } \\
\text { material) un rol protagónico en el desarrollo } \\
\text { de la creatividad nacional (meta) (PC1, p.23). }\end{array}$ & $\begin{array}{l}\text { La cultura nos pertenece(relacional atributivo) } \\
\text { a todos, y su construcción y renovación } \\
\text { permanente (localización temporal) } \\
\text { es(proceso relacional atributivo) una tarea } \\
\text { de la cual ningún chileno tiene que restarse } \\
\text { (relacional atributivo), porque nuestra } \\
\text { identidad se enriquece con todas las miradas } \\
\text { y con el sello de la diversidad (PC2, p.18). }\end{array}$ \\
\hline \multicolumn{2}{|c|}{ Construcción selectiva } \\
\hline $\begin{array}{l}\text { Se define a la cultura (objeto del discurso) } \\
\text { como una construcción emparentada con la } \\
\text { noción de nacionalidad. }\end{array}$ & $\begin{array}{l}\text { Se define a la cultura (objeto del discurso) } \\
\text { como una construcción emparentada con la } \\
\text { noción de nacionalidad. }\end{array}$ \\
\hline \multicolumn{2}{|c|}{ Esquematización estructurante } \\
\hline El arte y la creatividad como núcleo cultural. & La nacionalidad como núcleo cultural. \\
\hline \multicolumn{2}{|c|}{ Naturalización } \\
\hline $\begin{array}{l}\text { La cultura como propia de creadores y } \\
\text { artistas. }\end{array}$ & Cultura y nacionalidad como identidad. \\
\hline \multicolumn{2}{|c|}{ Anclaje } \\
\hline $\begin{array}{l}\text { La noción de cultura como tarea de artistas es } \\
\text { útil para argumentar la mayor participación de } \\
\text { la ciudadanía. }\end{array}$ & $\begin{array}{l}\text { La relación cultura, nacionalidad e identidad } \\
\text { funciona como impositivo para la participación } \\
\text { de la ciudadanía. }\end{array}$ \\
\hline \multicolumn{2}{|c|}{ Preconstruidos culturales (PCC) } \\
\hline $\begin{array}{l}\text { Relación nacionalidad-cultura. } \\
\text { Relación artistas-cultura. }\end{array}$ & Relación nacionalidad-cultura. \\
\hline
\end{tabular}

Fuente: Elaboración propia. 
sexos y se asegura que las propiedades del lenguaje contemplan, de por sí, la universalidad humana. Pero considerando que los objetivos de este estudio han pretendido desvelar en qué medida la política cultural chilena puede ser promotora de cambios o continuadora de representaciones hegemónicas, ha sido preciso acudir a estrategias que permitieran evidenciar dentro de los discursos la raíz de la invisibilidad de las mujeres en el período 2011-2016.

La visibilización de las mujeres a nivel lingüístico ha sido un terreno de lucha feminista ampliamente cuestionado por las institucionalidades de la lengua, aunque en el mundo político el lenguaje inclusivo ha tenido un eco insospechado y altamente dudoso. El problema de la representación no es exclusivo de la ausencia sino también del tipo de presencia, porque una excesiva aparición dentro de los discursos no asegura una jerarquización diferente a la otorgada a los sexos. Y es desde ese crucial aspecto que no tiene cabida un básico análisis sobre enunciación, sino de los aspectos contextuales y conceptuales que ocultan la latencia de las estrategias de la dominación sobre el género femenino.

Las diferencias de género han sido construidas a partir de una diferencia biológica tan estudiada como discutida, aunque desde las políticas públicas actuales esa diferencia no desvaloriza a las mujeres sino que se acude a una "discriminación positiva" que permite un acceso equitativo a los bienes proporcionados a todos los ciudadanos. Si nos sostenemos desde esa base, parece extraño que la histórica desigualdad entre hombres y mujeres continúe siendo una referencia para la interrelación social; por lo tanto, quizás el conflicto esté en una escasa modificación de las ideas sobre cultura y sobre lo que entendemos por ser mujer o ser hombre.

La cultura de la diferencia no ha modificado los esquemas de representación y no ha traspasado el umbral de las concepciones hegemónicas, a pesar de que existan figuras emblemáticas que supuestamente confirman lo contrario. La política cultural es, desde su institucionalización, una referencia clara de lo fácil que es hacer desaparecer a las mujeres de la escena social, porque no se han construido los mecanismos que aseguren nuestra presencia fuera de los espacios domésticos y reproductivos. $Y$ esa es una construcción que debe ser indudablemente instalada en las bases culturales de la sociedad, por medio de la representación de las mujeres como sujetos de acción y no como beneficiarias de los que otros han hecho. La política cultural, por lo tanto, debería ser considerada como un terreno crítico para alcanzar la equidad de los géneros y el soporte para la construcción de una nueva representación social de los géneros.

Podemos coincidir en que entre los conocimientos cristalizados socialmente se encuentran, como primera barrera, los roles de género atribuidos a cada sexo. Esto se evidencia cuando se coloca como plano comparativo el desarrollo entre hombres y mujeres, otorgando a estas últimas el beneficio de ser reconocidas como "jefas de hogar" (PC1). Se trata, además, de un lugar obtenido gracias a la generosa disposición de un país del cual se supone formábamos parte antes de ser consideradas fuerza de trabajo, por lo tanto no somos solo beneficiarias sino además constructoras de esa posibilidad. Ningún derecho social ha sido obtenido por gracia; todos y cada uno de ellos han sido ganados en la disputa con las 
clases dominantes. Sin embargo, es recurrente encontrar estas disposiciones discursivas en los documentos tanto políticos como educativos. Las batallas ganadas de las mujeres nunca han sido reconociblemente ganadas por ellas, y eso transgrede el derecho fundamental de toda persona a ser reconocida como agente de su propia historia, imponiéndose una atribución de empoderamiento inestable y siempre posible de revocar.

Siendo la cultura y las artes el objeto del discurso en ambos documentos, su definición es el marco que delimita los objetivos que como políticas culturales puedan proponer. El límite que ofrece una identidad nacional -en la cual las mujeres son "jefas de hogar" pero no artistas- es el marco perfecto que, apoyado en la profesionalización del arte y la cultura dado en toda Iberoamérica (Mariscal Orozco 2007), sirve a la política de derecha para dejar fuera de representación a las mujeres. Su omisión en la Política Cultural 2011-2016 no es la ausencia de las mujeres en la sociedad chilena; es su recolocación en el lugar que el poder hegemónico a destinado para ellas. Las mujeres no están presentes como profesionales, como creadoras, como gestoras, porque según la concepción tradicional del arte nunca lo han estado y su presencia no tiene cabida.

Si el discurso de la Política Cultural 2011-2016 puede ser considerado, a todas luces, como excluyente para las mujeres, es porque su concepción de cultura está arraigada en la más antigua y obsoleta definición de arte. Se trata de una selección de elementos que estructura una representación de lo que es cultura alrededor de un núcleo explícito, el "masculino creador", el gran hacedor de la tradición y la cultura. No ha de parecer extraño que existiendo referencias más actuales hayan sido seleccionados de textos escritos cuarenta años atrás, de manera que no solo se valida la exclusión de las mujeres, sino que también se retorna a la cultura elitista por clases.

Se podría considerar que el diseño de la política cultural del último período es propia de los sectores conservadores (la derecha chilena) que diseñaron esta propuesta, quienes, según la opinión pública, son quienes avalan las jerarquías religiosas y sociales (Pardo 2009) en las cuales las mujeres tienen un rol reproductivo y doméstico. Pero la revisión de la Política Cultural 2005-2010 arroja que esto es casi una resultante natural de sus errores de representación. Esto puede o no ser entendido como tal, considerando que quizás no existía una referencia acabada de la perspectiva de género ni de las estrategias para la representación social de las mujeres. Sin embargo, esta advertencia ya había sido formulada en la década de los ochenta por las teóricas feministas; la ruptura con la relación familia-mujer-hogar era un cambio fundamental para la transformación cultural, y podemos verlo ahora que han pasado más de tres décadas y la desigualdad de las mujeres sigue siendo un problema país.

Supuestamente el rol del Estado es el de contravenir la estructura hegemónica que impide el desarrollo de nuevas miradas sobre el mundo (Aguirre 2007). A pesar de esto, como expone Deborah Tannen (2008), la propia relación con el Estado no es simétrica. Los juegos entre ejercicio de poder y solidaridad ofician como referencias poco claras para atribuir a sus acciones la capacidad de salvaguardar el libre acceso de la sociedad a las distintas formas de concebir la realidad. El Estado, en tanto formula su discurso, construye, delimita y no sugiere, y 
por ello es determinante cómo estipula la idea de géneros y por qué parece cada vez más peligroso atenernos a sus definiciones de lo que a cada sexo le corresponde por derecho.

Sin negar la creación de instituciones para proteger la vulnerada seguridad de las mujeres, es paradójico considerar que las mismas estructuras de poder que limitan la "categoría" de mujeres sean las que permitan nuestra emancipación (Butler 2007), una emancipación hasta ahora restringida a su identificación sexual y, en menor medida, a su condición de ciudadana. Los avances constatados a nivel jurídico y de protección han sido insuficientes para transformar culturalmente al país, porque se han sostenido en los cuerpos sexuados y no en sus acciones sociales fuera de ello. La Política Cultural chilena no hace eco a la perspectiva de género, y sólo enuncia vaga e impracticablemente sus postulados, teniendo el deber de cumplimentar los derechos de ciudadanía, en consideración a que su alcance, por menos reconocido que pueda estar, construye patrones de representación.

Esta invisibilidad de las mujeres y el reconocimiento de la cultura como propia de lo masculino, se vuelve inoperativa como herramienta social y como mecanismo de cambio. La institución pasa de ser un organismo evaluador e informante de la realidad social a ser un garante de las decisiones políticas adoptadas, sin asumir a nivel discursivo una responsabilidad como agente, y depositando en elementos culturales tales como el patrimonio o las obras de arte, esa responsabilidad. Esto último es el resultado de atribuir procesos propiamente humanos, como los materiales y los mentales, a productos sociales, lo cual genera una condición en la que, como sociedad, dependemos de algo elaborado previamente y $\sin$ posibilidades de replantear, objetar o reconstruir nuestra noción de realidad.

El mayor cambio cultural, y el más necesario para la constitución políticas públicas para todos y todas, es el de la representación. Más que la creación de nuevas instituciones que fomenten la protección de la integridad física y moral de las mujeres, es necesario revisar cómo argumentar esa necesidad sobre la base de lo que, a estas alturas, desborda la noción de cultura propuesta por la institucionalidad del Estado chileno. Las mujeres conforman, y siempre lo han hecho, un conjunto activo en la creación artística del país y, evidentemente, en su desarrollo cultural. Esto, independientemente de las atribuciones de género que les hayan sido otorgadas socialmente, e incluso por sobre las definiciones hegemónicas de lo que es arte y cultura.

Sería deseable constatar que la vuelta a la democracia, los avances tecnológicos en comunicación global y la llegada de una mandataria a la Casa de Gobierno hayan repercutido en las formas de construcción discursiva dentro de la política, y que la tan ansiada perspectiva de género sea evidente a nivel de diseño y gestión. Sin embargo, que esto no haya ocurrido es un fiel reflejo de que las representaciones sociales pueden sostenerse en el tiempo más allá de lo previsible, y se apoyan indirectamente en otras representaciones ancladas a la tradición.

Si el tipo de representación de las mujeres está ligado a lo familiar, dentro de un parámetro que considera la cultura como bien móvil y amplio, sin enunciar su potencial de producción fuera de ello, la reducción de los márgenes del arte y 
la cultura y el apego a su definición tradicional, automáticamente resta toda posibilidad de construir discursos que contribuyan a una sociedad consciente de las distinciones entre diversidad y diferencia. Por último, niega, por sobre todo, que esas diferencias arraigadas en las atribuciones de género compongan el principal factor para la desigualdad.

\section{Bibliografía}

Abric, J.. 2001. Prácticas sociales y representaciones. México: Ediciones Coyoacán.

Aguirre, L. 2007. "Políticas Culturales en Chile. Una mirada desde la economía". Revista de Estudios para el desarrollo social de la comunicación, 4: 319-338.

Alberdi, I. 1999. "El significado del género en ciencias sociales". Política y Sociedad, 32, 1: 9-21.

Antoine, C. 2011. "Control y evaluación de las Políticas Culturales en Chile". Revista UNIVERSUM, 26, 1:13-37.

Araya, S. 2002. "Las representaciones sociales: Ejes teóricos para su discusión". Cuaderno de Ciencias Sociales, 127. Costa Rica: FLACSO.

Banchs M. 2000. "Representaciones Sociales del género en el discurso político, el discurso práctico y el discurso académico. Representaciones Sociales, Memoria Social e Identidad de Género". Revista Akademos, II, 1, 59-76

.1998. "Representaciones Sociales, Memoria Social e Identidad de Género". Revista Akademos, 2, 1: 59-76.

Bastos, S. 2007. "Familia, género y cultura. Algunas propuestas para la comprensión de la dinámica de poder en los hogares populares". Familia y Diversidad en América Latina. Estudios de casos Robichaux, D. Buenos Aires: CLACSO, Consejo Latinoamericano de Ciencias Sociales.

Benavente, M. y Valdés, A. 2014. Políticas públicas para la igualdad de género. Un aporte a la autonomía de las mujeres. Santiago: CEPAL.

Bosque, I. 2012. "Sexismo lingüístico y visibilidad de la mujer". Pleno de la Real Academia de la Real Academia Española. Madrid. Recuperado de http://www.rae.es/sites/default/files/ Sexismo_linguistico_y_visibilidad_de_la_mujer_0.pdf

Braidotti, R. 2004. Feminismo, diferencia sexual y subjetividad nómade. Barcelona: Gedisa.

Brea, J. 2010. "Retóricas de la resistencia: Una introducción". Estudios visuales, 7: 7-13.

Butler, J. 2007.El género en disputa. El feminismo y la subversión de la identidad.

Barcelona: Paidós.

Calsamiglia, H. y Tusón, A. 1999. Las cosas del decir. Manual de análisis del discurso. Barcelona: Editorial Ariel.

Carbajal, I. 2002 "Traducción institucional y neologismos: el caso de 'genero'”. El español, lengua de traducción, Actas del I Congreso Internacional. Hernúñez, P. y González, L. Almagro: Comisión Europea/Agencia EFE. 177-393.

Cárdenas, C. 2014. "Jóvenes e (in)visibilización histórica: Modos de representación ideológica de la juventud chilena en el pasado (1970-1990)". Revista Signos, 27, 85: 217-244.

Checa, L., Lagos, C. y Cabalin, C. 2011. "El caso de Chile durante el gobierno de Michelle Bachelet. Participación ciudadana para el fortalecimiento de la democracia". Argos, 28, 55: 13-47.

Chourio, N. 2012. "Teoría de las representaciones sociales: discusión epistemológica". Revista de estudios culturales, 5,10: 197-212

Colaizzi 1990

Consejo Nacional de la Cultura y las Artes. 2011. Política cultural 2011-2016. Chile: CNCA.

2005. Política Cultural 2005-2010. Chile quiere más cultura. Chile: CNCA.

Díaz-Romero, P. 2010. "La dimensión de género en la administración Piñera”. La nueva forma de gobernar: La instalación. Chile: Fundación Equitas. Recuperado de http://library.fes.de/pdffiles/bueros/chile/07962.pdf

Eggins, S. 2002. Introducción a la lingüística sistémica. España: Universidad de la Rioja.

Eggins, S. y Martin, J. 2000. "Géneros y registros del discurso". El discurso como estructura y proceso. van Dijk, T. (Comp.). Barcelona: Gedisa. 335-371.

Foucault, M. 1999. El orden del discurso. Barcelona: Tusquets Editores.

Furtado, V. 2013. "El lenguaje inclusivo como política lingüística de género". Revista Digital, 5, 5: 48-70. Recuperado de http://revistas.unc.edu.ar/index.php/RDPL/article/view/8656

García Messenguer, A. 2001. “¿Es sexista la lengua española?” Panace@, 2, 3: 20-34. Recuperado de http://www.medtrad.org/ panacea/IndiceGeneral/n3_GarciaMeseguer.pdf

Ghio, E. y Fernández, M. 2005. Manual de lingüística sistémico funcional. El enfoque de M.K.A Halliday y R. Hassan. Aplicaciones a la lengua española. Santa Fe: Universidad Nac. del Litoral.

Giménez, G. 1981. Poder, Estado y discurso. Perspectiva social y semiológica del discurso político-jurídico. México: UNAM.

Grau, O., Delsing, R., Brito, E. y Farías, A. 1997. Discurso, 
género y poder. Discursos públicos: Chile 1978- 1993. Santiago: LOM.

Grize, J. 1996. Logiquenaturelle et Comunication. París: PUF. .1993. "Logique naturelle et représentations sociales".

Papers on Social Representations, 2: 151-159. Recuperado de http://www.psr.jku.at/

Güell, P. 2012. "La sociedad de los bienes signo y las políticas culturales: Los nuevos desafíos. Algunas notas sobre el caso chileno". Alteridades, 22, 44: 81-95.

Güell, P. y Peters, T. 2011 "Combinaciones y secuencias: apuntes para una metodología de evaluación de proyectos y políticas culturales". Políticas culturales: Contingencia y desafíos. Negrón, B. y Silva, M. (Eds.). Observatorio de Políticas Culturales, 1, 1: 41-61.

Gutiérrez Vidrio, S. 2003. "El campo de la comunicación desde las representaciones sociales". Anuario de investigación, 1: 401-413.

.2000. "El discurso político. Reflexiones teóricometodológicas". Cultura y discurso, 10: 109-125.

Guzmán, V. 2001. La institucionalidad de género en el estado: Nuevas perspectivas de análisis. Santiago de Chile: CEPAL.

Halliday, M.A.K. 1982. El lenguaje como semiótica social. La interpretación social del lenguaje y del significado. México: Fondo de Cultura Económica.

Illanes, M. 2012. Nuestra historia violeta. Feminismo y vidas de mujeres en el siglo XX: una revolucion permanente. Santiago: LOM Ediciones.

Jäguer, S. 2003. "Discurso y conocimiento: aspectos teóricos y metodológicos de la crítica del discurso y del análisis de dispositivos". Métodos de análisis crítico del discurso. Wodak, R. y Meyer, M. Barcelona: Gedisa. 61- 141.

Jodelet, D. 1986. "La representación social: fenómenos, conceptos y teoría". Psicología Social II. Moscovici, S. Barcelona Paidós.

Juliano, D. 2001. "Modelos de género a partir de sus límites: la prostitución". Multiculturalismos y género. Un estudio interdisciplinar. Nash, M. y Marre, D. (Eds.). Barcelona: Bellatera. 87-115.

Kirkwood, J. 2010. Ser política en Chile. LOM Ediciones.

Lagarde, M. 1996. "El género", fragmento literal: 'La perspectiva de género'. Género y feminismo. Desarrollo humano y democracia, España: horas y HORAS. 13-38.

Lamas, M. 1999. "Usos, dificultades y posibilidades de la categoría género". Papeles de Población, 5, 21: 147-178.

Lechner, N. 1981. "Acerca del ordenamiento de la vida social por medio del Estado". Revista Mexicana de Sociología, 43,(3): 1079-1102.

Logiódice, M.J. 2012. "Políticas Culturales, la conformación de un campo disciplinar. Sentidos y prácticas en las opciones políticas", Documentos aportes administración pública y gestión Estatal, 12,18: 59-87.

Mariscal Orozco, J. 2007. Políticas culturales. Una revisión desde la gestión cultural. México: UDG Virtual.
Martín Rojo, L. 2003. "El análisis crítico del discurso. Fronteras y exclusión social en los discursos Racistas". Análisis del discurso. Manual para las ciencias sociales. Íñiguez Rueda, L. Barcelona: Editorial UOC. 157-189.

Mengo, R.I. 2009. "Género y política. Las presidentas de Chile y Argentina". Mediaciones Sociales, 4: 191-224.

Montecino, S. 1993. Madres y huachos. Alegorías del mestizaje chileno. Chile: Editorial Cuarto Propio.

Moscovici, S. 1979 "El Psicoanálisis, su imagen y su público". Buenos Aires: Huemul.

Mozekjo, T. y Costa, R. 2000. "La circulación de los discursos". Sincronía, 5, 17.

Muñoz del Campo, N. 2011."La reforma cultural en Chile: un ejemplo de polarización en la gestión de una Política Pública". Revista Chilena de Administración Pública, 18: 61-91.

Nivón, E. 2013. "Las políticas culturales en América Latina". Hegemonía cultural y políticas de la diferencia. Buenos Aires: CLACSO.

Ortner, S. 2006. "Entonces, ¿Es la mujer al hombre lo que la naturaleza a la cultura?" Revista de Antropología Iberoamericana, 1: $12-27$

1972. "Is female to male as nature is to culture?" Woman, culture, and society. Rosaldo, M. y Lamphere, L. (Eds.). California: Stanford University Press. 68-87.

Pardo, N. 2009. "Discurso público y la construcción del poder. Axiología en la representación mediática del discurso de Álvaro Uribe Vélez". Oralia, 12: 129-153.

Paredes, F. 1995. "¿La médica o la médico? Una aproximación sociolingüística a la elección de género”. Verba hispánica, 5: 7987.

Potter, J. y Edwards, D. 1999. "Social Representations and Discursive Psychology: From Cognition to Action". Culture \& Psychology, 5(4): 447-458

Sánchez, L. 2011. "Elementos para el análisis del discurso político en el escenario internacional". Revista Internacional de Pensamiento Político, 6: 419-433.

Santander, P. 2011. "Por qué y cómo hacer Análisis de Discurso". Cinta moebio, 41: 207-224.

Scott, J. W. 2008. Género e historia. México: Fondo de Cultura Económica.

Serret,S. 2006. El género y lo simbólico. La constitución imaginaria de la identidad femenina. México: Instituto de la Mujer.

Tannen, D. 2008. "La relatividad de las estrategias lingüísticas: repensando el poder y la solidaridad en el género y en la dominación". La manzana de la discordia,. 3, 2: 91-105.

Tubert, S. 2003. Del sexo al género. Los equívocos de un concepto. Madrid: Ediciones Cátedra.

Van Dijk, T. 2005. "Política, ideología y discurso". Quórum Académico, 2 (2): 15 - 47.

2002. "Conocimiento, elaboración del discurso y educación”. Escribanía, 8: 5-22. .1997. "Discurso, cognición y sociedad". Signos. 8

22: $66-74$ 
Vera, A. 2009. "Una crítica feminista a la Madre Pública Postdictatorial: los discursos de género en la campaña presidencial de Michelle Bachelet". Nomadías, 9: 111-129.

Weatherall, A. 2002. Gender, language and discourse. USA y Canadá: Routledge.
Wodak, R. 2015. "Gender and Language: Cultural Concerns". International Encyclopedia of the Social \& Behavioral Sciences. Wright, J. (Ed.). 688-703.

Zapata-Barrero, R. 2010. "Diversidad y política pública". Reflexiones sobre la diversidad (es). del Viso, N. (Coord.). 93- 104. 